\section{The prophylactic use of octreotide in a patient with ovarian carcinoid and valvular heart disease}

Jim T. Watson MD FRCPC, Neal H. Badner MD FRCPC, Mohamed J. Ali MD FRCPC
This case report describes the use of octreotide, a long-acting somatostatin analogue, in the management of a patient with an ovarian carcinoid tumour and severe cardiac valvular disease. This patient underwent laparotomy and tumour resection without complication. Anaesthesia was induced with midazolam, fentanyl, and vecuronium, and maintained with isoflurane as well as additional fentanyl and vecuronium. However, we feel that it was the use of octreotide that prevented a life-threatening crisis intraoperatively, and recommend its use in patients with carcinoid syndrome undergoing anaesthesia and surgery.

Cette histoire de cas décrit l'utilisation de l'octréotide, un analogue à longue action de la somatostatine, dans le traitement d'une patiente présentant une tumeur ovarienne carcinoide et une maladie cardiaque valvulaire sévère. Cette patiente a subi une laparotomie et une résection de la tumeur sans complication. L'anesthésie fut induite avec le midazolam, fentanyl et vécuronium et maintenue avec l'isoflurane et des doses additionnelles de fentanyl et de vécuronium. Cependant, on pense que l'utilisation de l'octréotide a empêché les problèmes peropératoires et on recommande son utilisation chez les patientes ayant un syndrome carcinoïde et devant subir une anesthésie et une chirurgie.

Carcinoid syndrome, first described in $1954,{ }^{1}$ is characterized classically by episodic flushing, bronchospasm, diarrhoea and right-sided valvular heart lesions. These

\section{Key words}

HORMONES: somatostatin analogue, octreotide; SEROTONIN: carcinoid syndrome;

SYNDROMES: carcinoid; SURGERY: ovarian carcinoid.

From the Department of Anaesthesia, University Hospital, University of Westem Ontario, London, Ontario.

Address correspondence to: Dr. N. H. Badner, Department of Anaesthesia, University Hospital, PO Box 5339, London, Ontario, N6A 5A5. symptoms occur as the result of ectopic release of vasoactive substances (e.g., serotonin, histamine, bradykinins) from a tumour of neuro-ectodermal origin. During anaesthesia and/or surgery, release of these substances can lead to severe hypotension, hypertension or bronchospasm. ${ }^{2}$ We report the case of a patient with a large ovarian carcinoid tumour and associated cardiac involvement. She underwent a tumour resection without incident after being managed preoperatively with octreotide, a recently released synthetic somatostatin analogue ${ }^{3}$ which inhibits ectopic hormone release.

\section{Case report}

A 54-yr-old, $62 \mathrm{~kg}$ housewife presented with an abdominal mass of three months' duration and a $12 \mathrm{~kg}$ weight loss. She had noted flushing of her face, chest and hands on exertion or when anxious, as well as intermittent diarrhoea and constipation. She also noted a marked decrease in her exercise tolerance. She was taking no medications and had no known allergies.

Physical examination revealed normal vital signs throughout the preoperative period. There were multiple telangectasias on her face and upper chest. Her extremities were cool and cyanotic. Breath sounds were normal. Jugular venous distention extended to the earlobe and cannon waves were present. First and second heart sounds were normal. A systolic ejection murmur grade III/VI was noted along the left sternal border, and a grade IU/VI pansystolic murmur was noted over the apex. A firm lower abdominal mass was palpable and measured approximately $20 \mathrm{~cm}$ by $25 \mathrm{~cm}$.

Laboratory investigation revealed that haemoglobin, electrolytes, BUN, creatinine, and glucose concentrations were normal. Urinary 5-hydroxy indolacetic acid (5-HIAA) was $1660 \mu \mathrm{mol} \cdot 24 \mathrm{hr}^{-1}$ (normal $=0$-52). Ultrasound of the pelvis showed a pelvic mass measuring 25 by 15 by $11 \mathrm{~cm}$. Two-dimensional echocardiography revealed a dilated right atrium and ventricle, a tricuspid valve with rigid thickened cusps fixed in the open position with severe regurgitation, mild to moderate insufficiency 
of the mitral and aortic valves, with normal myocardial contractility. The chest $x$-ray was normal. Pulmonary function testing showed an FEV 1 of $1.71 \mathrm{~L}$ with an FEV $/$ FVC of 58 per cent. Following ventolin therapy this improved to an $\mathrm{FEV}_{1}$ of $2.38 \mathrm{~L}$ and $\mathrm{FEV}_{1} / \mathrm{FVC}$ of 77 per cent.

Preoperatively, the patient received ranitidine $150 \mathrm{mg}$ $\mathrm{PO}$, and octreotide acetate $150 \mu \mathrm{g} \mathrm{SC}$ both on the night before surgery and on the following moming, as well as diphenhydramine $50 \mathrm{mg} \mathrm{IM}$, and diazepam $10 \mathrm{mg}$ PO, on call to the operating room. Monitors included an electrocardiogram, oscillometric blood pressure cuff, end-tidal $\mathrm{CO}_{2}$, pulse oximeter, arterial line, Swan Ganz catheter, oesophageal stethoscope and temperature probe.

Anaesthesia was induced with $6 \mathrm{mg}$ midazolam, $10 \mathrm{mg}$ vecuronium, and $400 \mu \mathrm{g}$ fentanyl. The trachea was intubated and the lungs were ventilated. Anaesthesia was maintained with $\mathrm{O}_{2}, 0.2-1.5$ per cent inspired isoflurane, and a total of $17 \mathrm{mg}$ vecuronium and $950 \mu \mathrm{g}$ fentanyl. The intraoperative course was haemodynamically uneventful; heart rate varied from $60-90$ beats $\cdot \mathrm{min}^{-1}$ systolic blood pressure $110-150 \mathrm{mmHg}$, systolic pulmonary artery pressure $26-31 \mathrm{mmHg}$, central venous pressure 11-14 mmHg and cardiac output $2.7-3.4 \mathrm{~L}$. $\min ^{-1}$ (cardiac index $1.6-2.1 \mathrm{~L} \cdot \mathrm{min}^{-1}$ ). Blood loss was estimated at $1200 \mathrm{ml}$.

Postoperatively, the patient remained overnight in the Intensive Care Unit as the lungs were ventilated. The trachea was extubated and she was transferred to the ward the next morning. Recovery was uneventful, and urinary 5-HIAA was undetectable one week postoperatively.

\section{Discussion}

Carcinoid tumours are rare with a reported incidence of $8 / 100,000^{4}$ with only one to two per cent of these being of ovarian origin. ${ }^{5}$ The presence of carcinoid syndrome occurs in less than 25 per cent of all patients. 'This is due to their gastrointestinal origin and subsequent hormone deactivation in the liver in more than 85 per cent of cases. ${ }^{4}$ In these patients, liver metastases must occur for symptoms to be present. An ovarian tumour has systemic venous drainage and therefore does not have this hepatic hormonal deactivation and symptoms are present in almost half of these patients. ${ }^{6}$ It was on this basis that our patient had such severe multisystem disease and urinary 5-HIAA levels of more than 30 times normal.

Most reports of the anaesthetic management of carcinoid syndrome describe the use of one or more agents which block the action of the various ectopic vasoactive substances. However, although histamine, serotonin and bradykinins are the best known, there are more than 35 peptides that these tumours can secrete, ${ }^{4}$ making the choice of an appropriate blocking agent difficult. We used the antihistamines diphenhydramine and ranitidine because of our familiarity with them and their relatively minor side effects. We could have added the serotonin antagonists cyproheptadine or ketanserin, although both of these drugs have not always prevented intraoperative crises. ${ }^{2,7.8}$ One could also use aprotinin, a kallikrien inhibiter, and block bradykinin conversion to its active form. However, it too has failed to prevent hypotension and bronchospasm when given prophylactically. ${ }^{9}$

We feel that octreotide acetate is a more useful agent as it has been shown both to bock the hormonal release ${ }^{10,11}$ and to inhibit the action of circulating peptides ${ }^{7}$ by the inhibition of either phosphatidylinositol ${ }^{10}$ or adenylate cyclase. ${ }^{12}$ In the five patients reported by Ahlman et al. ${ }^{10}$ and Roy et al. ${ }^{13}$ undergoing hepatic resection, none had an intraoperative crisis when they received octreotide prophylactically. One of the four patients subsequently underwent another procedure two months later without receiving octreotide. Following the same anaesthetic induction sequence this patient developed severe hypotension and bronchospasm. This patient responded quickly to intravenous octreotide as did another patient reported by Marsh et al. whose hypotension had been refractory to fluid loading, phenylephrine, calcium chloride, and epinephrine. Recently, a patient with metastatic pulmonary carcinoid tumour underwent emergency surgery after having received octreotide. ${ }^{14}$ This patient developed a hypertensive crisis, but the octreotide was given at induction of anaesthesia and not before surgery as we and others have done. ${ }^{10.13}$ The crisis was successfully treated with intravenous octreotide and ketanserin. These patients all had symptoms due to liver metastases, as opposed to our patient who had an ovarian tumour, and none had evidence of cardiac valvular disease. In view of this, and our patient's smooth intraoperative course we recommend the use of octreotide in the management of carcinoid patients both prophylactically and in the treatment of an acute intraoperative crisis. A controlled trial proving octreotide's effectiveness would be ideal, but it would be difficult to perform.

Octreotide acetate (Sandostatin-Sandoz) is a synthetic octapeptide which has two D-amino acids added to the basic somatostatin molecule. This allows it to retain the essential action of somatostatin yet resist degradation from serum peptidases. This increases its half-life to 1.5 $\mathrm{hr}$ from one to three minutes, and enables it to be given by subcutaneous injection instead of as a continuous infusion. ${ }^{3}$ A dosage of $150 \mu \mathrm{g}$ SC TID given to patients with malignant carcinoid syndrome led to symptomatic improvement within hours. ${ }^{15}$ When used preoperatively Ahlman et al. ${ }^{10}$ and Roy et al. ${ }^{13}$ used dosages of $100 \mu \mathrm{g}$ SC BID for two days in their patients. Given intravenously, $50 \mu \mathrm{g}$ rapidly reversed the hypotensive crisis reported 
by Marsh $e t a l .^{2}$ Adverse effects which include pain at the injection site, nausea, vomiting, diarrhoea and abdominal discomfort are uncommon at dosages of 300 to $450 \mu \mathrm{g}$ per day and are usually mild. ${ }^{3}$ There is no evidence of serious haematological, neurological or renal toxicity even when used in much higher dosages. ${ }^{16}$

Our anaesthetic induction sequence was chosen to minimize hormonal release. Fentanyl, ${ }^{17}$ midazolam, ${ }^{18}$ and vecuronium, ${ }^{19}$ have all been shown not to release histamine. This combination was similar to that used in the patient described by Ahlman et al. ${ }^{10}$ and discussed earlier, who had not received octreotide prophylaxis and subsequently experienced a severe carcinoid crisis. This adds to our belief that the use of octreotide rather than the anaesthetic technique was the more important factor in our patient's stable intraoperative course.

Valvular heart disease due to an ovarian carcinoid tumour has been reported. ${ }^{6}$ Although the patient had significant tricuspid valve disease requiring replacement, the pulmonary valve involvement was mild, and the mitral valve was not diseased at all. This patient underwent an initial hysterectomy and bilateral salpingooopherectomy and subsequently a tricuspid valve repair. However, no description of the anaesthetic management or the intraoperative course of either procedure was given.

In summary, we describe the use of octreotide, a somatostatin analogue, in the management of a patient with an ovarian carcinoid tumour and severe cardiac valvular disease who underwent laparotomy and tumour resection without complication. Such a patient was at high risk of developing a life-threatening crisis intraoperatively. We consider that our use of octreotide acetate most likely prevented this from happening. We therefore recommend its use in patients with carcinoid syndrome undergoing anaesthesia and surgery.

\section{References}

1 Mason RA, Steane PA. Carcinoid syndrome - its relevance to the anesthetist. Anaesthesia 1976; $31: 228-42$.

2 Marsh HM, Martin JK, Kvols LK et al. Carcinoid crisis during anesthesia: successful treatment with a somatostatin analogue. Anesthesiology 1987; 66: 89-91.

3 Abramowicz $M$. Octreotide a synthetic somatostatin. The Medical Letter 1989; 31: 66-8.

4 Miller JK. Carcinoid syndrome and the APUD concept. Seminars in Anesthesia 1987; 3: 228-37.

5 Strickman NE, Rossi PA, Massumkhani GA, Hall RJ. Carcinoid heart disease: a clinical, pathological, and therapeutic update. Curr Prob Cardiol 1982; 6: 1-42.

6 Sworn MJ, Edlin GP, McGill DA, Mousley JS. Tricuspid valve replacement in carcinoid syndrome due to ovarian primary. Br Med J 1980; 280; 85-6.
7 Kvols LK, Martin JK, Marsh HM, Moerte CG. Rapid reversal of carcinoid crisis with a somatostatin analogue. N Engl J Med 1985; 313: 1229-30.

8 Castheley PA, Jablons M, Griepp RB, Ergin MA, Good$\operatorname{man} K$. Ketanserin in the preoperative and intraoperative management of a patient with carcinoid tumour undergoing tricuspid valve replacement. Anesth Analg 1986; 65: 809-11.

9 Miller R, Patel AU, Warner RRP, Parnes I. Anaesthesia for the carcinoid syndrome: a report of nine cases. Can Anacsth Soc J 1978; 240-4.

10 Ahlman H, Ahlung L, Dahlstrom A, Martner J, Stenquist $O$, Tylen $U$. SMS 201-995 and provocation tests in preparation of patients with carcinoids for surgery or hepatic arterial embolization. Anesth Analg 1988; 67: $1142-8$.

11 Reichlin S. Somatostatin. N Engl J Med 1983; 309: 1495-501; 1556-63.

12 Monteith $K$, Roaseg $O P$. Epidural anacsthesia for transurethral resection of the prostate in a patient with carcinoid syndrome. Can J Anaesth 1990; 37: 349-52.

13 Roy RC, Carter RF, Wright PD. Somatostatin, anaesthesia, and the carcinoid syndrome. Peri-operative administration of a somatostatin analogue to suppress carcinoid tumour activity. Anaesthesia 1987; 42: 627-32.

14 Hughes EW, Hodkinson BP. Carcinoid syndrome: the combined use of ketanserin and octreotide in the management of an acute crisis during anaesthesia. Anaesth Intensive Care 1989; 17: 367-70.

15 Kvols LK, Moertel CG, O'Connell MJ, Schutt AJ, Rubin J, Hahn RG. Treatment of the malignant carcinoid syndrome. Evaluation of a long-acting somatostatin analogue. N Engl J Med 1986; 315: 663-6.

16 Arosio M, Bazzoni N, Ambrosio B, Faglia G. Acute hepatitis after treatment of acromegaly with octreotide. Lancet 1988; 2: 1498.

17 Bailey PL, Stanley TH. Pharmacology of intravenous narcotic anesthetics. In: Miller RD (Ed.). Anesthesia 2nd ed., New York: Churchill Livingstone Inc. 1986; 745-97.

18 Reves JG, Fragen RJ, Vinik HR, Greenblatt DJ. Midazolam: pharmacology and uses. Anesthesiology 1985; 62: $310-24$.

19 Morris RB, Cahalan MK, Miller RE. The cardiovascular effects of vecuronium and pancuronium in patients undergoing coronary artery bypass grafting. Anaesthesiology 1983; 58: 438-40.

20 Patel AU, Miller R, Warner RRP. Anesthesia for ligation of the hepatic artery in a patient with carcinoid syndrome. Anesthesiology 1977; 47: 303-5.

21 Nielsen MS, Manners JM. Valve replacement in carcinoid syndrome. Anacsthesia 1979; 34: 494-9. 